\title{
Mothers in Cases of Incest in Turkey: Views and Experiences of Professionals
}

\author{
Filiz Kardam • Emine Bademci
}

Published online: 1 March 2013

(C) Springer Science+Business Media New York 2013

\begin{abstract}
This paper aims to understand how professionals view non-offending mothers in cases of incest. Its data is based on a larger qualitative research project with 98 professionals in Turkey, including both frontline workers and those who join the process after the disclosure of abuse and are contacted professionally in incest cases. In spite of the differences in their views, the interviewed professionals have acknowledged the critical role of the mother in various phases of incest from disclosure of abuse to the treatment of the victim. However, they have also pointed out the insufficiencies and ambivalences of the mothers in terms of dealing properly with incest by underlining their economic and social vulnerability. The results reflected that the mothers need to be perceived in another light, understood better and empowered according to their needs to become vital partners within the support system combating incestuous abuse.
\end{abstract}

Keywords Child abuse $\cdot$ Mother blame $\cdot$ Non-offending mothers · Combating incestuous abuse · Mothers' empowerment

Although sexual abuse and incest are important problems in the world, statistics about their prevalence are difficult to obtain since most of these cases remain hidden. Yet, the numbers at hand are sufficient to reflect its worldwide significance. According to the World Health Organization

F. Kardam

Department of Political Science and International Relations, Çankaya University, Ankara, Turkey

e-mail: kardamfiliz@yahoo.com

E. Bademci $(\bowtie)$

Department of Political Science, Bilkent University,

06800 Ankara, Turkey

e-mail: bademci@bilkent.edu.tr
(World Health Organization 2004), in 2002, 150 million females and 73 million males experienced different forms of sexual abuse before age 18. Furthermore, in the research on women's health and violence against women in 10 countries with diverse cultural and rural-urban settings, best estimates indicated that the prevalence of sexual abuse before age 15 varied from 1 to $21 \%$ (World Health Organization 2005). Most frequently mentioned perpetrators were male family members other than a father or stepfather.

In Turkey, the only statistic about the prevalence of sexual abuse from the national research on domestic violence against women (Kadının Statüsü Genel Müdürlüğü 2009) indicates that $7 \%$ of women reported sexual abuse before age 15 . Thirty percent of these were abused by their male relatives. Recent research in Turkey on incest cases includes mainly quantitative studies based on the analysis of court files and forensic evidence, and clinical studies of sexual abuse cases and studies on the procedures of medical investigations in such cases (Atılmış et al. 2008; Aydın and Çolak 2004; Cantürk and Cantürk 2006; Demirci et al. 2008; Gunduz et al. 2011). The role of mothers in incestuous families, however, has not been studied specifically.

Perhaps as a preliminary for further research on this subject, this study centers upon how professionals dealing with incest in Turkey view the non-offending mothers of the incestuously abused children and the dynamics involved in the ways they view these mothers. How the professionals view, approach, and support the mothers may considerably shape the role the mothers play in disclosing and dealing with incest and becoming an important partner within the system of combating incestuous abuse. Such an improvement in the role that mothers play in turn can make a difference in the lives of incest victims. The paper begins with a literature review, then the findings of the study are presented and discussed, and it concludes with the implications of the study with some suggestions. 


\section{Literature Review}

The role of non-offending mothers in incest cases has received a great deal of attention. Research suggests that although it is very rarely the victim's mother who perpetrates incest (Kim et al. 2007); it is usually the mother who becomes the focus of attention when incest is disclosed (Tamraz 1997). The mother is viewed simultaneously as the object of blame for failing to protect her children, control the perpetrator, and safeguard her family, and as the subject of hope for rescuing the victim and maintaining the home (Tamraz 1997).

A gradual but decisive transition has been observed in the literature on the role of mothers. The transition is both theoretical and methodological and it is a transition from blaming the mothers to seeing them as secondary victims (Lafleur 2009) or from non-emphatic approaches to emphatic approaches (Womack et al. 1999) or from opinion-based information to research-based information (Tamraz 1997). Non-emphatic or blaming approaches rely on analyses based on small samples of mothers, lack comparison groups, use simplistic theoretical models, and make statements without sufficient data support about the individual pathology of mothers and their contribution to the origin and maintenance of the sexual abuse (Womack et al. 1999).

Blaming or non-emphatic approaches maintain that mothers play a role of collusion in incest. The family dysfunction approach describes the mother in the pre-disclosure phase of incest as a person who lacks the skill or the sense of responsibility for looking after her child and also is unwilling to have sex with the husband for reasons of her own (Jacobs 1990, p. 502). The outcome is that he then turns to the daughter or the son, and thus, the mother is considered guilty for this relationship of incest. This approach supports the notion that the mother is in some way responsible for the acts of the father.

Emphatic approaches, on the other hand, point to a shift in method and perspective. Rather than focusing on the individual psychopathology of mothers, they argue that the role of mothers should be understood contextually from a feminist perspective, which places great emphasis on structural dynamics such as the dominance of patriarchy and unequal power relations in societies and between males and females. Therefore, they argue that mothers are not the source or colluder of incest; on the contrary, they are usually unaware of the abuse and when they discover it, they actively support their children, to varying degrees, because of the complexity of the issue, which may result in some ambivalence on their part. As an alternative to the term collusion, which has added to the stigmatization of mothers, Joyce $(1997$, p. 90) puts forward the term "diminished capacity to protect" to describe the behavior of some mothers without the moral judgment that "collusion" implies. Tamraz's (1997) evaluation of the literature on non-offending mothers reveals that information about mothers has been predominantly opinion-based, which characterizes mothers as a troublesome population in the sense of not being able to carry out their responsibilities as mothers. However, this literature is increasingly becoming a researchbased one that describes the mothers objectively and acknowledges the heterogeneity of the mothers' roles, actions, and reactions in incest cases.

Feminist analysis of family power relations that stresses the centrality of both the economic mode of production and patriarchy also treats the family as dysfunctional; yet, the source of this dysfunction is not the mother, but the structural arrangements and unequal power relations that place the mother in a powerless and vulnerable position (Jacobs 1990). Another approach put forward by Briere and Elliot (1993) reverses the causality to argue that it is not the family pathology that leads to incest, but, the other way around; it is the experience of incest that leads to pathology in the family.

The professionals intervening in incestuous abuse are the people who are in a position to deal with the incident of incest, such as teachers, social workers, pediatricians, police officers, lawyers, judges, prosecutors, forensic experts, therapists, psychologists, and psychiatrists. According to Crawford (1999), the literature draws a theoretical image of mothers that greatly influences professionals and often leads to dramatic changes in their performances. However, development of the non-blaming research and literature has contributed to the practice and performance of the professionals dealing with the problem of incest; they are no longer using the concept of "collusion" (Joyce 2007). They are also persuaded, increasingly, to view mothers as a special group comprised of women who live very complex and multi-dimensional lives and act accordingly (Alaggia 2002, pp. 42-43).

Incestuous abuse is a particularly serious form of child sexual abuse and represents a violation of norms that transcend culture (Koverola 2007, p. 141). However, intervention in incestuous abuse varies in different settings and there is no model of intervention that transcends cultures. In some societies, the state takes action by law to protect the incest victim and to provide therapeutic intervention (Abu Baker and Dwairy 2003). However, in some other societies, for various reasons, the family, rather than the state, is the entity that usually takes or is expected to take responsibility for children's safety and survival; family members are thought to possess a collective self and are not individuated from their family of origin (p. 110). As the family is taken as a collective self, incidents such as incest are thought to be a source of shame for the whole family; thus, attempts are made to keep the incest a family secret. That is why the socio-cultural milieu, in other words, the character of the community surrounding the family and the linkages with the 
relatives and acquaintances, is a critical factor influencing mothers' behavior upon the disclosure of the incestuous abuse.

Culture influences how mothers make meaning of the sexual abuse and the actions they take. Alaggia (2002) has found that mothers coming from families that believe in, and adhere to, the practices of rigid patriarchal norms will often have serious value conflicts about maintaining the family bonds. They will have value conflicts about the ties between the perpetrator and the victim. More importantly, they will have significant fear of being isolated from their larger family and ethnic community. The Alaggia study also indicated that culture, religion, and cultural beliefs about preserving family unity influence how mothers perceive the abuse and how they act after their children's disclosure of incest (p. 42).

Contrary to the earlier literature describing mothers of incest victims as passive and weak, studies in later years demonstrate that a majority of mothers accept that incest happened and actively support their children when they disclose intra-familial sexual abuse (Goretsky and Smith 1992). Crawford (1999) examined the studies on the mothers in families of intrafamilial sexual abuse and called attention to several important findings. Firstly, many mothers who participated in studies did support their children during and after disclosure and were within a relatively normal range of personality functioning. Secondly, maternal support and/or the mother-child relationship were critical in predicting the short-term adjustment and outcome of sexually abused children. Thirdly, both the mother-children relationship and the mother's ability to be supportive affected the children's level of distress and their psychosocial functioning after disclosure (p. 67). Therefore, failing to include the mother in the support of the child in the post-disclosure phase of incestuous abuse is likely to limit the extent and the nature of the child's recovery (Breckenridge and Baldry 1997, p. 76).

\section{Method}

This study is part of a larger research project, "Understanding the Problem of Incest in Turkey," conducted in 2008-2009 by the Population Association in Turkey with the support of the United Nations Population Fund. The objective of this larger research project was to increase the visibility of incest in Turkey as well as comprehending and improving the system requirements for combating incest and the failing or deficient components of the existing system. As it aims to understand the system which is encountered by the victims, interviewees have been selected from among the professionals employed at institutions that are, or may be, approached by incest victims. The project researchers collated the professionals' experiences, know-how, views, and recommendations and this article specifically focuses on the mothers in incestuous cases as they are related by these professionals. Thus, one of the aims of this study is to underscore the important place of mothers in supporting and treating the victims, preventing revictimization, and bringing an end to the victimization cycle among generations.

\section{Methodological Approach}

This is a qualitative study that aims to generate new knowledge on a sensitive issue of which little is known in Turkey. The research question was approached with the principles of constructivist grounded theory. In the light of the new ideas and perspectives on qualitative research methodology and the changes in the application of the grounded theory in the last 40 years (Charmaz 2006, 2009; Corbin 1998, 2009; Glaser and Strauss 1967; Goulding 1999; Strauss and Corbin 1998), our decision was to approach knowledge as socially constructed, occurring under certain conditions and affected by the interaction between the research participants and the researchers. We attempted to understand the meaning behind what the participants told us, keeping in mind the existence of multiple realities.

As researchers, our position was the position of a subjective insider, open, flexible, and active in construction and interpretation of data. As insiders, we share the same social and cultural context with our research participants (the professionals). We also share, as women living in the same society, at least part of the experiences of the mothers in incestuous families. Taking a reflexive stance toward the research process, we tried to understand what was being said about the mothers, to interpret the meaning beyond the explanations and evaluations of the professionals and to reach some generalizations with the awareness that they are relative, partial and conditional.

\section{Procedures}

Data for this study was collected through unstructured and semi-structured interviews carried out with people from different professions, including both frontline workers and those who join the process after the disclosure of abuse who are or might be contacted professionally in cases of incest. They include teachers (guidance counselors and classroom teachers), physicians (psychiatrists, pediatricians, pediatrics surgeons, forensic experts, and public health experts), midwives, police, judges, prosecutors, lawyers, psychologists (child and adult psychology), social services experts, sociologists and representatives of the non-governmental organizations. The sample selected was a purposive sample with the aim of reaching at least one person from each professional group in each city and they were contacted via 
relevant institutions and people. The field study was carried out in six cities-Adana, Ankara, Diyarbakır, Erzurum, Istanbul, and Kocaeli. Ninety-eight people in total were interviewed in these six cities; the interviews were recorded and the recording for each interview was on average one and a half hours. Qualitative data analysis software NVivo, Version 7.0 was used in preparing the data for analysis.

The interviews were implemented as guided conversations and the informants were treated as partners rather than objects of study (Rubin and Rubin 1995). The interviews aimed to locate answers to the questions about how incest is experienced, the characteristics of sexual perpetrators and victims, why incest is kept hidden, and how it is disclosed. The role of the mother in this process became an issue of discussion in the narrations of the professionals. They also provided data about the ways by which the victims reach the professionals; the forms of legal, psychological, social, and medical support provided to victims and perpetrators following the disclosure of the incident and the functions of the professionals and their respective institutions in identifying and solving the problem (see Table 1 for a summary of interview guidelines). The interview guidelines aimed to collect data on different aspects of incestuous abuse and more specifically about the professionals' experiences with cases of incest.

\section{Results}

In this study, not only are the incest cases observed by the professionals diverse, they are also viewed differently by the professionals from various disciplines. Therefore, what the professionals observe and narrate in relation to the mothers of incest victims is usually limited to their professional background and what kind of work and services are expected from them. The findings below reflect how the professionals viewed the mothers in incest cases and the reasoning behind their views.

\section{Blaming the Mothers}

In their accounts of the incest cases with which they dealt, the professionals blamed the mothers for not being able to disclose the incest (or believe and accept it when the victim revealed the incest) and to protect their children from further harm. However, at the same time they expressed the view that they were probably expecting too much from the mother regarding the incestuous abuse. They were careful about not denouncing the mothers as "colluders," although they believed that mothers are usually aware of everything happening at home and to their children (meaning that they are also aware if there is incestuous abuse) and still they are compliant and refrain from addressing the problem and taking any action.

Some of the professionals claim that mothers have a significant role in cases that are not revealed or reported to official authorities. They also emphasize that the mother is weak and is not in a position to protect her child. A sociologist expresses the matter as: "In all cases, mothers know. I have come across 116 cases and in each case the mother knows. After all, the child goes to the mother...Mothers don't hear, don't talk at all; they don't hear." A psychologist emphasizes that it is quite unlikely for the mother not to notice a child's symptoms of incest:

The changes in the child's behavior or the father's staying too long in the child's room or while having a bath or changing the baby's diaper [...] The child definitely shows indication. In such cases, it is impossible for the child not to experience some psychological problems. It is unlikely that the mother does not notice these problems.

In other instances, some of the professionals emphasize the mothers' traditionally defined roles in the family as the person settling all kinds of disputes (including domestic violence) among the family members. In such terms, a guidance counselor, explaining the passivity of the mother, described her position as managing to hold the existing conditions under control in the family:

The mother was expressionless and in denial of the event. In other types of abuse or violence, which is also abuse within the family, mothers in general handle the situation. They want to handle it $[. .$.$] they do$ not want anything to get destroyed and their family to fall apart. [...] She is asked to be quiet and not to talk, and to draw a veil over the subject because if she remains silent about it, no one will bring it up. That was the mother's approach.

\section{Socio-Economic Weaknesses of the Mother}

Most of the professionals have noted the mothers' social and economic conditions as an explanatory factor for not being active in the disclosure of incest. They also consider this as a factor for not being able to support their children in the later phases of dealing with the incest. Their emphasis was on the mothers' dependence (especially economic dependence) on their husbands or on other powerful male members of the family (including their elder sons). The main problems brought forth are the issues of income poverty, lack of education, load of domestic work, exposure to domestic violence, and fear of husbands.

The professionals have described the situation of women by using such phrases: "They do not know what to do," 
Table 1 Content of the questions that guided the interviews with the professionals

\begin{tabular}{|c|c|}
\hline General questions & Specific questions \\
\hline Professional experience & City, institution, position, duration \\
\hline Experience in dealing with cases of incest & $\begin{array}{l}\text { Descriptions of, and views of, the perpetrator, the victim, the mother, other family members, } \\
\text { family-home environment, the process of the abuse, disclosure, post-disclosure procedures/ } \\
\text { process and the role of the mother, and impressions of the mother's role and experience of the } \\
\text { event }\end{array}$ \\
\hline $\begin{array}{l}\text { Professional process, duties, and } \\
\text { responsibilities }\end{array}$ & $\begin{array}{l}\text { The channels through which the victims reach the institutions/professionals; the ways in which the } \\
\text { cases are disclosed; the responsibilities of the institution and the professionals there; the kind, } \\
\text { and content of, the support provided to the victims, other institutions, and professionals for } \\
\text { cooperation; follow-up of cases }\end{array}$ \\
\hline $\begin{array}{l}\text { Problems, cooperation, and equipment in } \\
\text { dealing with incest cases }\end{array}$ & $\begin{array}{l}\text { Training of the professionals, character of the duty (voluntary or appointed), difficulties } \\
\text { encountered in different phases of dealing with incest cases, support for professionals in the face } \\
\text { of the stress caused by the work done }\end{array}$ \\
\hline Opinions on incest cases & $\begin{array}{l}\text { The extent and prevalence of the problem, reasons behind undisclosed cases (society, law, religion, } \\
\text { culture, economy, gender, quality of the services, competence of the professionals), reasons } \\
\text { behind incest cases, the change in the extent of the sensitivity to incest cases since the } \\
\text { professional started working in the institution, possibilities for preventing incest, suggestions of } \\
\text { the professionals }\end{array}$ \\
\hline
\end{tabular}

"they have nowhere to go," "they have no social security," "they put up with them," "they are trapped socially and culturally," "they are worried about who will take care of the family if the father is imprisoned," "they are dependent individuals," "they are under pressure and threat," "they have been exposed to violence and oppressed," and "they are in need of their husbands for survival." Emphasizing the economic weakness of the mother and the fact that she has no income, a lawyer has stated that this leads the mother to remain silent and, in a way, to collaborate in the incident, underscoring the importance for the family to be supported financially:

When you send the father to prison, you need to do something to protect the family. You have to set up such a system for the mother to earn a living so that she can make an appeal to authorities easily and provide evidence, not turn a blind eye to this situation. The mother is also afraid of being starved. [...] Namely, she is in such despair that [...] she ignores [the incest].

The professionals also stated that the mother is weak and vulnerable not only because she is economically dependent, but also is exposed to violence in the family. As a result of this, mothers may become totally incapable. A social services expert explained the state of a mother in one of the incest cases she followed as such:

She [the abused child] shared it [the incest] with the teacher at school and also with her mother. But her mother did not consider it as abuse, of course. She was so weak and poor. I mean, even if she recognized the incest, she would not speak about it because there was violence in the house, an intense physical violence.

\section{Preserving the Unity of the Family}

Most of the interviewees stated that the mothers suppose that they are protecting the unity of their families by keeping incest secret. By doing this, they also assume that there will be less harm done to their children. The mothers, in addition to being dependent on their husbands economically, also do not want to be seen as "women breaking up their marriages and homes" in the eyes of the society. The interviewees assert that the sexual abuse cases within the family are less likely to be revealed compared to those outside the family because women give priority to the continuation of their families.

Some of the professionals have emphasized the importance of the family in Turkish society and stated that giving priority to the family is a cultural characteristic. The following are examples of how the interviewees (a lawyer and a guidance counselor) interpret the role of "family" for incest cases:

In the [incest] cases I know about, the mothers are likely to deny it, in the fear that the unity of the family will break down or people in the neighborhood will speak ill of the family; therefore, they avoid this issue consciously in order to cover it up. They protect the family, family honor, and name instead of protecting their child.

They [the mothers] are also exposed to violence themselves; they just do not do anything. Their children are exposed to violence and they do not take any action either. They do not talk about it and do not do anything. In my opinion, they think that protecting the family and ensuring its continuation is the most important thing. 
Moreover, it has been related that in the cases where the sons of the family happen to be the perpetrators of incest, not only the mothers, but also other family members make a greater effort to conceal the incidence. If they fail to conceal, they try to make sure that official legal proceedings will not commence. The honor of the sons as the persons to carry the family name becomes more important than the harm given to other children (mostly females) as victims of incest.

Mothers' attempts to protect the honor and unity of family are usually supported by their social circle. Because of the pressure posed by the relatives, women sometimes change their decisions and retract their statements about the incest cases. The case below, related by a psychologist, provides a prime example of how relatives can influence the mother's behavior:

When she was in her last year at high school, she woke up one night feeling her father touch her and found her father ejaculating on her body. She $[\ldots]$ immediately told her mother about it; there was already violence [...] in the household. The mother accepted that it is incest. Then the girl went to the police station right away in her pajamas. She told the police what had happened; thereupon, the father was arrested at once. [...] But after a while, the mother started to visit the father in prison as a result of the pressure from the family, uncles, and aunts, though she believed her daughter and everything was proven. Then the family and uncles said "our family is disgraced" and they made the girl withdraw her complaint by pressuring her [and the father was released]. The girl entered university in another city. When she came back home, the father continued to do the same things. But the mother told her to shut up, though it happened a second time. The uncles and the aunts, they all [...] said "you have devastated the entire family" and the girl went to the police station again and escaped from home. She escaped in order not to withdraw her complaint, because they would make her withdraw it.

\section{Mother's Feelings Toward the Perpetrator and the Victim}

Another issue indicated by the professionals, especially by psychologists and psychiatrists, is about the effects of the mother's feelings toward the perpetrator and the abused child. In relation to this, if the woman is strongly attached to the perpetrator emotionally and tends to idealize him, this may create difficulties for her to pay attention to, and believe, what the victim says about the abuse and to take action.

Moreover, it was stated by some psychiatrists and psychologists that some mothers might have weak emotional ties, negative relations, or problems in communicating with their children. This may go as far as protecting the aggressor and blaming the victim. However, it is an issue that was not brought up by other professionals interviewed. With the research data at hand, it is difficult to comment upon its prevalence. The observations of two psychiatrists in this direction are as follows:

A 16-to-17-year-old girl was brought to us. It was an incest case and many of the deeds of the perpetrator occurred in front of the mother, including sexual intercourse. The father-daughter... The mother says for her daughter, "This girl causes everything to happen [...] because this girl causes my husband to lose control." [She thinks so] because the man has explained it like that: "When I see this girl, I lose control, I do not know what to do." And the woman believes that.

She [the victim] said, "Since I couldn't sit properly, I used to lean towards the dining table. My mother used to scold me. Once they took me to a doctor, the area between my legs was bruised, but the doctor and my mother said, "who knows what kind of mischief you got yourself into." This child was 8-years-old. For example, the mother defended herself by saying "this girl already knows a lot about sexual things. She seduced her father."

Some professionals also report that the mothers' history of sexual abuse in her own childhood is a factor influencing her attitude toward the incest. Although the number of reported cases of the mothers experiencing incest in their childhood was quite small in the interviews, the professionals' observations of these cases reflect that such mothers adopt a rather passive attitude toward incest, overlooking it and trying to escape from a situation that gives them emotional pain. Professionals reporting on such cases have stated that the mother's own childhood experience of abuse had negative impact on the disclosure of her child's incestuous abuse.

\section{Is Incest Women's Fault?}

One of the professionals expressed a different point of view about the meaning of incest for some mothers. She has stated that departing from the position of women in the society and the "proper" sexual conduct expected from them in general, sometimes women themselves may evaluate the incest case in which their daughters are involved as the "women's fault." The mothers, if they internalize the dominant values in the society about the role of women acting as provokers in sexual assault/abuse cases, may tend to see their daughters not as victims, but as seducers who provoked the perpetrators and, therefore, at least partially, are responsible for this misdeed. She tries to describe the 
feelings of these women stating that such internalization could lead the mothers to blame their daughters:

$[\ldots]$ it is regarded as the women's fault, which means the women regard this as something that sticks to them. When the women, for example, are even verbally abused, they think as if they have done something to deserve it just because of being a woman. There is such an understanding in our society that unless a woman is indulgent or encourages the man, he will not dare to molest her. Unfortunately, this notion is quite established in our society.

\section{Mothers' Ambivalence and Need for Support}

The cases narrated by the respondents indicate that the mothers in incestuous families, no matter in which circumstances incest occurs, endure many dilemmas from the very moment they become aware of, or at least suspicious about, the sexual abuse. The mothers usually vacillate between decisions and actions ranging from refusing to acknowledge the event and ignoring it to intervening and supporting the victim actively. Usually, their situation turns into a severe trauma, especially when there is no one to give them support. The professionals described the position of mothers as ambivalent; the mothers found themselves fluctuating between feelings of guilt and responsibility regarding their children in particular and the whole family in general. A lawyer has defined the experiences of a mother as an extended and stressful state of indecision where she "straddles" between the wish to protect her child (the victim) no matter what happens and the effort to save her family from collapsing:

They [the mothers] say "I will take this issue to the bitter end; I will not let him do this to my child." Three days pass. They say "well, the unity of my family is important, she/he is the only child, this process must proceed properly, and he [the perpetrator] has the financial power." Then two more days pass, and they say "yes, but I must be trustworthy." I mean in this process, they are confused a lot [...] they have nobody to support them; they might also be threatened by the relatives of the father as well as by their own children since some of the children get upset and accuse their mothers. The women straddle a lot. They become indecisive about how they will lead their lives afterwards. This can be observed at all levels. It is not different for educated women who have occupations $[\ldots]$.

It was related by the professionals that mothers are, on the one hand, indecisive and hesitant to appeal to legal authorities as they try to keep the case secret in order not to bring disgrace on the family. On the other hand, they try to protect their children against the aggressors at home through the strategies they develop on their own. The professionals also stated that some mothers try to stop the molestation of their children by getting divorced and taking the children away from home. In the cases in which they cannot divorce, they try to find ways such as not leaving the children alone with the aggressors at home, sleeping together with them, or locking their bedroom doors at night. An activist at a women's non-governmental organization (NGO) explains the experiences of such mothers reflecting their fears and dilemmas, but at the same time their efforts to protect their children in every way possible:

She says "all I can do is not to leave my children alone with their father [...] I cannot start legal proceedings; I cannot do anything because he would kill me or deny it all together." [...] The woman is divorced but the man is still seeing his children; he always wants to see the sons; their daughter is older and she hates her father. The mother says "Well, I have never been able to talk to my daughter about it. Did he do anything to her? Why does she show such reaction to her father?" She continues "but I try not to let my sons go; they are too young. I tell them to come back if their father is alone at home or if their grandparents are not there; all I can do is this."

Contrary to most cases related by the professionals, the following case reported by a psychiatrist exemplifies an active, supportive mother who succeeded to handle the incest case with the least harm to her child:

Well, we had such a family. For example, the mother informed the police as soon as she became aware of the case and we kept a close watch on that child only for 2 or 3 months because there were no symptoms. It is because the person who is still present amongst those to whom the child feels attachment, namely the mother, had protected her. Well, the father was punished and sent to prison; a new life with her mother was arranged for the child and at this phase, the social services experts stepped in and their monthly supervision began. [...] That child showed no psychiatric symptoms; she just attended the activities there. She did not receive intensive psychiatric treatment since her self-respect was not seriously damaged. She said "I have a mother and she did what she had to do. My father did something bad and he was punished for it."

\section{Discussion}

This study explores the professionals' view of mothers in families of incestuous abuse. They are key figures in the 
system that combats incest; however, this study has limitations in that it relies on their views. In the first place, although in some instances the information regarding the "mother" was based on the direct observations and experiences of the professionals in the field, the professionals also conveyed their views and generalizations based on the incest cases they may have heard about from others. Therefore, in the latter cases, they were not actually talking about "how certain mothers have acted," but conveying a professional view about "what mothers under such circumstances can do in general." Another limitation was that most people who apply to relevant public institutions with complaints that incestuous abuse happened are generally from the lower socio-economic strata. Therefore, the professionals have based their views on women who are economically vulnerable, uneducated, and unemployed. Because of this, they rarely spoke of active knowledgeable mothers who support their children effectively. As a result, the mothers in incestuous families were often identified with qualifications particular to a certain group of mothers, although all of the incest families do not belong to that group. Therefore, it is not possible to discern the heterogeneity of incestuous families and the differences of mothers from their accounts.

The professionals all view the mothers in critical positions in terms of disclosure of incest and support of the victims. They have based their views on the critical role of the mother mainly on their assumption that the mothers are aware of everything that is going on in the family. Therefore, it is impossible for the mother to be unaware of incest in the family. Even if she herself cannot sense it, it is usually the mother in the family to whom the victim tries in some way to communicate such problems. It is also thought that when the mother is submissive, ignores the incident or does not believe the victim, then the victim also feels insecure and retreats into silence. This leads to further delay in the disclosure of abuse. However, discovery of incest is a process where many factors interplay and not all mothers come to make sense of the hints correctly or at the same length of time (Plummer 2006). Even if the mother suspects that something is amiss, depending on her conditions and all other internal and external factors affecting her, this may take time for her to accept that incest has occurred and start taking action.

To understand the power and weakness of mothers in the face of incestuous abuse of their children, the social context should also be taken into account. A recurrent question, related to social context, about the impact of the socioeconomic status on the occurrence of incestuous abuse is whether such abuse is more common in families of lower economic status, although most studies do not confirm the assumed linkages between sexual abuse and lower socioeconomic status. On the contrary, it has been revealed that incest can prevail in all socio-economic and cultural settings. However, most researchers point out that incest cases are generally more hidden and remain unreported in families of higher socio-economic status and that is why it is thought to be rarer in such settings (Çavlin-Bozbeyoğlu 2009 , p. 17). In addition, families from higher strata might have their own effective ways of dealing with incestuous abuse such as getting help from private institutions or being able to visit psychologists at their private practices.

An important aspect of the social context is the disadvantaged position of women in society compared to men in Turkey. For example, the illiteracy rate, in 2010, was $9.9 \%$ among females and $2.2 \%$ among males age 6 and older (Kadının Statüsü Genel Müdürlüğ̈ 2012). Labor force participation, in 2011, was $44.9 \%$; for women it was $28.6 \%$ and for men $71.6 \%$. Of working women, $35.2 \%$ are so called "family workers without any payment." The disadvantaged position of women and the fact that the professionals in the study generally encountered mothers from socio-economically lower classes have made them perceive the mothers as powerless.

Furthermore, some of these mothers were also exposed to violence, and violence against women also continues to be a vital problem in Turkey. In 2008, research into domestic violence on a national basis in Turkey showed that $39.3 \%$ of women were physically abused by their husbands or partners at some point in their lives; $41.9 \%$ were confronted with physical or sexual violence; $15.3 \%$ with sexual violence, and $44 \%$ with emotional violence. Among every 10 women with high school or upper level education, three experience physical or sexual violence (Kadının Statüsü Genel Müdürlüğü 2009). As reported by the professionals violence made the mothers even weaker physically and emotionally. As such, they could not find strength to do anything except struggle to survive. Previous research also reflects that the existence of different forms of violence (physical and psychological abuse, psychological threat, etc.) is common in incestuous families (Alaggia 2002, p. 46; Candib 1999, p. 196). The research into domestic violence in Turkey also shows that women under intense and long-lasting violence at home hesitate to leave their home or the perpetrator (Kardam and Yüksel 2009). They may wait until their children get older. In those cases, it is usually not the anxiety about economic survival that keeps the women trapped, but the fear of their husbands, thinking that they may kill them or their children. This kind of anxiety and fear may also be true in the case of mothers in incestuous families.

In addition, the concern of mothers to protect the family unity was brought forth by the professionals as a determinant of mothers' role in cases of incest. If the mothers come from cultural backgrounds that give primary importance to family unity, no matter what happens, their reactions toward the abuse of their children will take shape accordingly 
(Alaggia 2002). Family has an important place in the Turkish culture. The fact that families are getting smaller in structure has, to some extent, reduced the material dependencies of family members on one another; however, research reflects that mutual dependencies in the psychological sense continue (Kagitcibasi 2002, pp. 23-31). In general, it is possible to talk about closely-knit family ties and a collectivist family culture. Some recent research indicates that although there is a change in the attitudes of people in terms of their educational level, settlement area, living styles, etc., over $80 \%$ consider the family as the first place to apply when confronted with material or moral problems (Aile ve Sosyal Araștırmalar Genel Müdürlüğü 2010). Again, 90 \% express that they can face all kinds of hardships for the good of their family. Another factor playing a positive role on collectivist family culture is marriage with close relatives which is still a common practice. In 2006, $20.9 \%$ of the marriages were with close relatives (Turkish Statistical Institute 2011, pp. 4-9).

Although comparative studies on the effect of cultural context on the mothers' behavior in incestuous families in Turkey do not exist, research on domestic violence offers some possibility of tracing similar relationships. It was observed that women who had experienced violence themselves advise their daughters - at least in the initial phases of violence - to behave properly and maintain their family under all circumstances (Kardam and Yüksel 2009, pp. 160-161). As a factor affecting the behavior of the mother facing the incest, the mother's childhood trauma was reported by the professionals. The findings by Kim et al. (2007, p. 349) have reflected that for the mothers who experienced childhood sexual abuse themselves, the difficulties and challenges in this situation may be more pronounced. However, the differences in the reactions of mothers with childhood sexual abuse histories from the mothers with no such stories in terms of providing support to their children are still being investigated (Kim et al. 2010), and the reasons for adopting a passive attitude in such cases may depend on many factors.

\section{Mother's Need for Empowerment}

Incest brings trauma into the lives of mothers. They may vacillate between protecting their children and protecting the unity of the family. They may find themselves deficient not only in their role as mothers, but also as wives. They pass through a painful process trying to give meaning to incest and finding ways to struggle against it. This process and the strategies adopted by the mother in the pre- and post-disclosure phases are influenced by many factors both internal/individual and external/social as well as the duration and the severity of the incestuous abuse itself (de Young 1994). In their research on post-disclosure responses of nonoffending mothers whose children were abused by their partners, Bolen and Lamb (2007) studied the relationship between ambivalence and parental support. Although traditionally ambivalence is considered an indication of inadequate support, their findings have shown that mothers can have contradictory feelings and behavior toward their children after the disclosure of sexual abuse, but still they are supportive.

How the professionals understand and evaluate the mother's inadequacy and inconsistency is important in terms of their relations with the mother and where they place the mother in the process of solving the problem. While defining mothers most of the time as "needy, powerless, and incapable," and "not knowing what to do and where to go," it was not always clear from the expressions of the professionals whether they consider the vulnerabilities of women as a result of the structure of a patriarchal system that incorporates gender inequalities and discrimination in many respects or as a result of individual incompetence of the women themselves. Moreover, the professionals emphasized mostly economic insufficiencies of women, and for most of them, empowerment meant mainly provision of economic support.

If the complexity of the mother's social and psychological state is underestimated by the professionals and they evaluate her ambivalence as "ignorance and weakness," then they may consider her as an obstacle to solving the problem of incest. Empowering the mothers will help them to take earlier action in incest cases and find the courage to expose the incest.

The professionals may also learn to abandon their image of the all-powerful mother who is responsible for everything going on in the family and may focus on the reasons behind mothers' reactions and constraints. In the end, the efforts of professionals to understand the mothers better, their ways of approaching them with an appropriate level/type of sensitivity, and providing them with proper support and care in the process of solving the problem will ease the trauma confronting the mother and the incest victims as well. By focusing on the mothers regarding the solution of incest cases, this paper argues that mothers should be conceived as vital partners in the support system that has to be carried out with the cooperation of institutions and professionals together. Therefore, mothers need to be perceived from another perspective, understood better, with their similarities and their differences, and empowered according to their needs and capabilities.

\section{Implications of the Study}

In order to support the mothers and establish better cooperation with them, the professionals should be provided with necessary skills and know-how in their respective fields. To this end, higher education programs should be reorganized 
so that all professionals from related vocations are offered courses on gender awareness, rights of women and children, sexual health, and child abuse and incest. For those already in work life, in-service training programs must be provided on such topics, as well as programs for training those who will maintain the momentum of such courses by training others.

Furthermore, it would be beneficial to create opportunities among the professions for continual exchange of practical experience and problems. Since combating incest necessitates multi-disciplinary support, it is important for various professions to understand one another and be able to examine incest from different perspectives. Effective and functional reporting mechanisms that safeguard privacy and protect the individual safety of the professionals must also be developed in order to facilitate the reporting of incest, especially by those who are employed in the fields of healthcare and education and who are more likely to be effective in revealing such cases. The establishment of units in respective institutions must be ensured, such as the children's and women's commissions in the Bar Associations or the units dealing with child abuse and neglect in the hospitals. It is also important to develop standardized methods for appraising suspected cases and carrying out the necessary procedures following the revelation of incest. In addition, the NGOs which work in the field of combating domestic violence and sexual abuse should be recognized and supported as organizations empowering women and providing necessary guidance.

In order to increase the awareness of children, it is necessary that training for sexual abuse and sexual health begin in the very early years of their school life. This demands reorganization of school programs and training of the necessary staff to do this. Parents also need to be provided with training on related topics such as rights of children, psychosocial and sexual development of children, child abuse, and incest. Such training could be provided by local authorities in cooperation with relevant NGOs.

Parents should also be informed on laws related to violence and abuse as well as the organizations which provide guidance and support on issues of domestic violence and sexual abuse. It is very important, especially for the mothers, to have access to these institutions. When there is sexual abuse, both the victim and the mother should be able to obtain the necessary economic support as well as health controls and other rehabilitation services. In addition, traumatic character of incest events might also affect the professionals; therefore, they need to be provided with the necessary support, as well, in order to safeguard their wellbeing.

This study has also indicated the need for additional research in Turkey on incest and specifically on the mothers of incest victims. Most of the existing studies are investigations into the psychosocial conditions of incest victims through clinical cases or from court files. There are also a few studies on the perpetrators of sexual abuse and on prevention and rehabilitation processes. However, there is need for further research, especially for interdisciplinary studies on incest and specifically about perpetrators and non-offending mothers from different socio-economic groups, various types of families and with different incest experiences.

Acknowledgments This study is based on data from a larger research project, "Understanding the Problem of Incest in Turkey," which was funded by the United Nations Population Fund and conducted by the Population Association, Turkey. We would like to thank the research team and the professionals interviewed for their participation and Alanur Çavlin-Bozbeyoğlu for her encouragement and support for this study. We intend this research to benefit victims of incest and their mothers.

\section{References}

Abu Baker, K., \& Dwairy, M. (2003). Cultural norms versus state law in treating incest: a suggested model for Arab families. Child Abuse \& Neglect, 27, 109-123. doi:10.1016/S0145-2134(02)00505-7.

Aile ve Sosyal Araștırmalar Genel Müdürlüğü. (2010). Türkiye'de aile değerleri araştırması [Family values in Turkey]. Ankara: Manas Medya Reklam Hizmetleri.

Alaggia, R. (2002). Cultural and religious influences in maternal response to intrafamilial child sexual abuse: charting new territory for research and treatment. Journal of Child Sexual Abuse, 2, 4160. doi:10.1300/J070v10n02 03.

Atılmış, U. U., Gündüz, T., Karbeyaz, K., Balcı, Y., \& Oral, R. (2008). Ensest șüphesi içeren bir olguda tanı güçlüğ̈̈ [Difficulty in diagnosis of a case with high suspicion of incest: Case Report]. Türkiye Klinikleri Adli Tip Dergisi, 5, 156-161.

Aydın, B., \& Çolak, B. (2004). Samsun'da ağır ceza mahkemesine yansiyan cinsel suçlar [Sex crimes tried at the High Criminal Court in Samsun]. Adli Tıp Bülteni, 9, 11-18.

Bolen, R. M., \& Lamb, J. L. (2007). Can non-offending mothers of sexually abused children be both ambivalent and supportive? Child Maltreatment, 12, 191-197. doi:10.1177/1077559507300132.

Breckenridge, J., \& Baldry, E. (1997). Workers dealing with mother blame in child sexual assault cases. Journal of Child Sexual Abuse, 1, 66-80. doi:10.1300/J070v06n01_04.

Briere, J., \& Elliot, D. M. (1993). Sexual abuse, family environment and psychological symptoms: on the validity of statistical control. Journal of Consulting and Clinical Psychology, 2, 284-288. doi:10.1037/0022-006X.61.2.284.

Candib, L. M. (1999). Incest and other harms to daughters across cultures: maternal complicity and patriarchal power. Women's Studies International Forum, 2, 185-201. doi:10.1016/S02775395(99)00006-0.

Cantürk, G., \& Cantürk, N. (2006). Cinsel saldırı mağdurlarının muayene prosedürü [Examination procedure of sexual assault victims]. Cerrahi Tip Bilimleri Acil Tip Dergisi, 2(50), 49-55.

Çavlin-Bozbeyoğlu, A. (2009). Understanding the problem of incest in Turkey. Ankara: UNFPA and Population Association.

Charmaz, K. (2006). Constructing grounded theory. London: Sage.

Charmaz, K. (2009). Shifting the grounds, constructivist grounded theory methods. In J. M. Morse, P. N. Stern, J. Corbin, B. Bowers, 
A. E. Clarke, \& K. Charmaz (Eds.), Developing grounded theory: The second generation. Walnut Creek: Left Coast Press.

Corbin, J. M. (1998). Alternative interpretations: valid or not? Theory \& Psychology, 8, 121-128. doi:10.1177/0959354398081007.

Corbin, J. (2009). Taking an analytic journey. In J. M. Morse, P. N. Stern, J. Corbin, B. Bowers, A. E. Clarke, \& K. Charmaz (Eds.), Developing grounded theory: The second generation. Walnut Creek: Left Coast Press.

Crawford, S. L. (1999). Intrafamilial sexual abuse: what we think we know about mothers and implications for intervention. Journal of Child Sexual Abuse, 3, 55-72. doi:10.1300/J070v07n03 04.

De Young, M. (1994). Women as mothers and wives in paternally incestuous families: coping with role conflict. Child Abuse \& Neglect, 1, 73-83. doi:10.1016/0145-2134(94)90097-3.

Demirci, S., Doğan, K. H., Erkol, Z., \& Deniz, I. (2008). Konya'da cinsel istismar yönünden muayenesi yapılan çocuk olguların değerlendirilmesi [Evaluation of child cases examined for sexual abuse in Konya]. Türkiye Klinikleri Adli Tip Dergisi, 5, 43-49.

Glaser, B., \& Strauss, A. L. (1967). The discovery of grounded theory. Chicago: Aldine.

Goretsky, S. E., \& Smith, B. E. (1992). The controversial role of the non-offending parent in child sexual abuse cases. Children's Legal Rights Journal, 18, 18-22.

Goulding, C. (1999). Grounded theory: Some reflections on paradigm, procedures and misconceptions [Working Paper No. WP006/99]. Retrieved from http://www.wlv.ac.uk/PDF/uwbs_WP00699\%20Goulding.pdf

Gunduz, T., Karbeyaz, K., \& Ayranci, U. (2011). Evaluation of the adjudicated incest cases in Turkey: difficulties in notification of incestuous relationships. Journal of Forensic Sciences, 56, 438443. doi:10.1111/j.1556-4029.2010.01662.x.

Jacobs, J. L. (1990). Reassessing mother blame in incest. Signs: Journal of Women in Culture and Society, 3, 500-514. Retrieved from http://www.jstor.org/stable/3174425.

Joyce, P. A. (1997). Mothers of sexually abused children and the concept of collusion: a literature review. Journal of Child Sexual Abuse, 2, 75-92. doi:10.1300/J070v06n02 05.

Joyce, P. A. (2007). The production of therapy: the social process of construction of the mother of a sexually abused child. Journal of Child Sexual Abuse, 3, 1-18. doi:10.1300/J070v16n03_01.

Kadının Statüsü Genel Müdürlüğ̈̈. (2009). Türkiye’de Kadına Yönelik Aile İçi Şiddet Araştırması [Domestic violence against women in Turkey]. Ankara: Elma Teknik Basım.

Kadının Statüsü Genel Müdürlüğü. (2012). Türkiye’de kadının durumu [The status of women in Turkey]. Retrieved from http:// www.kadininstatusu.gov.tr/upload/mce/trde_kadin_2012_ekim.pdf
Kagitcibasi, C. (2002). Cross-cultural perspectives on family change. In R. Liljeström \& E. Ozdalga (Eds.), Transactions: Autonomy and dependence in the family (Vol. 11, pp. 19-38). Istanbul: Swedish Research Institute.

Kardam, F., \& Yüksel, I. (2009). Kadına yönelik aile içi șiddet: Sayıların ardındaki anlatılar [Perceptions about violence against women: Qualitative research results]. In Kadının Statüsü Genel Müdürlüğü (Ed.), Türkiye’de Kadına Yönelik Aile İçi Șiddet Araştırması [Domestic violence against women in Turkey] (pp. 103-185). Ankara: Elma Teknik Basım.

Kim, K., Noll, J. G., Putnam, F. W., \& Trickett, P. K. (2007). Psychosocial characteristics of non-offending mothers of sexually abused girls: findings from a prospective multigenerational study. Child Maltreatment, 12, 338-351. doi:10.1177/1077559507305997.

Kim, K., Noll, J. G., Putnam, F. W., \& Trickett, P. K. (2010). Childhood experiences of sexual abuse and later parenting practices among non-offending mothers of sexually abused and comparison girls. Child Abuse \& Neglect, 34, 610-622. doi:10.1016/ j.chiabu.2010.01.007.

Koverola, C. (2007). Perpetuating mother-blaming rhetoric: a commentary. Journal of Child Sexual Abuse, 1, 137-143. doi:10.1300/J070v16n01_09.

Lafleur, C. T. (2009). Mothers' reactions to disclosures of sibling sexual abuse. (Unpublished doctoral dissertation). Kansas State University, Manhattan, Kansas. Retrieved from http:// hdl.handle.net/2097/1370

Plummer, C. A. (2006). The discovery process: what mothers see and do in gaining awareness of the sexual abuse of their children. Child Abuse \& Neglect, 11, 1227-1237. doi:10.1016/j.chiabu.2006.05.007.

Rubin, H. J., \& Rubin, I. S. (1995). Qualitative interviewing: The art of hearing data. London: Sage.

Strauss, A. L., \& Corbin, J. (1998). Basics of qualitative research. Thousand Oaks: Sage.

Tamraz, D. N. (1997). Non-offending mothers of sexually abused children: comparison of opinions and research. Journal of Child Sexual Abuse, 4, 75-104. doi:10.1300/J070v05n04 05.

Turkish Statistical Institute. (2011). Women in statistics 2011. Ankara: Turkish Statistical Institute Printing Division.

Womack, M. E., Miller, G., \& Lassiter, P. (1999). Helping mothers in incestuous families. Women and Therapy, 4, 17-34. doi:10.1300/ J015v22n04 02.

World Health Organization. (2004). Preventing violence: A guide to implementing the recommendations of the World Report on Violence and Health. Geneva: Author.

World Health Organization. (2005). Multi-country study on women's health and domestic violence against women. Geneva: Author. 